\title{
Health in rural Sri Lanka: a cross-sectional survey of three rural districts
}

Upul Senarath ${ }^{1}$, Sanath Senanayake ${ }^{2}$, Sisira Pathirana ${ }^{2}$, Nadira Karunaweera ${ }^{2}$, Manuj C Weerasinghe ${ }^{1}$, Nalika S Gunawardena ${ }^{3}$, Ishanka P Munugoda ${ }^{4}$, Saroj Jayasinghe ${ }^{5}$, Priyani Amarathunga $^{6}$, Enoka Corea ${ }^{7}$, Varuni De Silva ${ }^{5}$, Deepika Fernando ${ }^{2}$, Ravindra Fernando ${ }^{9}$, Ariaranee Gnanathasan ${ }^{3}$, Mangala Gunatilake ${ }^{10}$, Sharmini Gunawardena ${ }^{2}$, Prasad Katulanda ${ }^{5}$, Senaka Rajapakse ${ }^{5}$, Nilakshi Samaranayake ${ }^{2}$, Yamuna Siriwardana ${ }^{2}$

(Index words: rural, health, communicable disease, non communicable disease, Sri Lanka)

\begin{abstract}
Introduction Sri Lanka has a predominantly rural population. However, there is a dearth of research on health and socioeconomic issues in this group.

Objective To describe basic socioeconomic characteristics and health profile in a rural population.

Methods A descriptive cross-sectional household survey was conducted in 1950 households in three rural districts, selected by a three-stage stratified cluster sampling method.

Results The population pyramid showed an ageing population (dependency ratio of $50 \%$ ). Only $39 \%$ had completed GCE (ordinary level). Unemployment rates were high (25\% males, $76 \%$ females). Agriculture and related work were main occupations. Most lacked amenities (e.g. $61 \%$ households lacked a refrigerator) and practiced inappropriate methods of waste disposal (e.g. open burning by $72 \%$ ). Household illnesses were frequent: episodes of acute illness within two weeks, injuries within past year and chronic illness were reported from $35.9 \%, 14.9 \%$ and $48.3 \%$ households. The prevalence of chronic diseases in adults $>20$ years were high: diabetes $13.5 \%$, hypertension $16.7 \%$ and
\end{abstract}

overweight/obesity $28.2 \%$. Of the males, $22.1 \%$ smoked and $12.3 \%$ took alcohol. Almost $25 \%$ adults chewed betel. Reports of snake bite, dog bites and suicide/ attempted suicide were seen in $15.5 \%, 9.7 \%$ and $3.0 \%$ households respectively.

Conclusions This study shows a unique clustering of health-related problems in rural Sri Lanka. This was characterized by demographic transition, burden from snake bites, chronic diseases and acute illnesses. There were resource limitations and low levels of education. Cohort studies and comparisons with urban areas will enable further elucidation of determinants of health and other issues in rural Sri Lanka.

\section{Introduction}

Sri Lanka has a predominantly rural population that is facing rapid changes in its social, cultural and physical environments [1]. These changes are likely to have favourable (e.g. improved socio-economic status) as well as adverse health impacts (e.g. effects of urbanization increasing the prevalence of non-communicable diseases). The changing lifestyles of people, major environmental changes including climate change, rapid urbanization,

Ceylon Medical Journal 2019; 64: 103-110

DOI: http://doi.org/10.4038/cmj.v64i3.8957

${ }^{1}$ Department of Community Medicine, Faculty of Medicine, University of Colombo, Sri Lanka, ${ }^{2}$ Department of Parasitology, Faculty of Medicine, University of Colombo, Sri Lanka, ${ }^{3}$ World Health Organization, Colombo, Sri Lanka, ${ }^{4}$ Menzies Institute for Medical Research, University of Tasmania, Australia, ${ }^{5}$ Department of Clinical Medicine, Faculty of Medicine, University of Colombo, Sri Lanka, ${ }^{6}$ Department of Pathology, Faculty of Medicine, University of Colombo, Sri Lanka, ${ }^{7}$ Department of Microbiology, Faculty of Medicine, University of Colombo, Sri Lanka, ${ }^{8}$ Department of Psychiatry, Faculty of Medicine, University of Colombo, Sri Lanka, ${ }^{9}$ Department of Forensic Medicine and Toxicology, Faculty of Medicine, University of Colombo, Sri Lanka, ${ }^{10}$ Department of Physiology, Faculty of Medicine, University of Colombo, Sri Lanka.

Correspondence: US, e-mail: <upul@commed.cmb.ac.Ik>. Received 20 May 2019 and revised version 2 September 2019 accepted 24 September 2019.

This is an open-access article distributed under the terms of the Creative Commons Attribution License, which permits unrestricted use, distribution, and reproduction in any medium, provided the original author and source are credited. 
population migration and constantly evolving microbial agents and disease vectors, pose new threats to the health of these population groups. The country has made dramatic achievements in the recent past, with either elimination of near elimination of many communicable diseases such as malaria, filariasis, Japanese encephalitis, and neonatal tetanus. However, other infections have emerged or re-emerged such as dengue, leptospirosis and leishmaniasis contributing to the country's disease burden $[2,3]$. The burden of non-communicable diseases, such as cardiovascular and cerebrovascular diseases, cancers, diabetes, alcohol and substance abuse, chronic kidneydiseases and respiratory diseases are rapidly increasing and account for over $70 \%$ of morbidity in the country, while traumatic injuries continue to be the leading cause of hospitalization [2, 4-6]. Mental health problems are also relatively common, especially in communities in the north and east of the country, which were predominantly affected by a previous conflict [7].

Though such average figures and trends are known, there is growing concern that rural areas of Sri Lanka have different patterns of illness and even far worse health indices. A literature review failed to reveal any comprehensive surveys carried out in the rural areas of the country. Large-scale surveys such as the Household Income and Expenditure Survey (HIES) do not capture adequate health data, and the identification of rural areas are through administrative classification that are based on the type of local government (e.g. areas governed by municipality and town councils are considered urban). However, this classification is imprecise and many areas classified as rural are in effect peri-urban.

We therefore planned a cross-sectional survey that would better characterize and reflect health of rural populations in Sri Lanka. For this purpose, we selected three of the poorest and remote rural administrative districts of Ampara, Moneragala, and Hambantota situated in the Eastern, Uva, Southern provinces respectively. The survey was designed to describe the morbidity and mortality patterns, health risks and selected determinants in this population. Moneragala lacks an urban council therefore, theoretically almost the whole population is rural. In the case of Hambantota and Ampara the estimated rural populations constitute $93.8 \%$ and $75.4 \%$ respectively [8]. The other factor considered in the selecting these districts were that they had all three major ethnic groups (i.e. Sinhala, Tamil and Muslim). Moneragala and Hambantota are predominantly Sinhalese areas $(97.1 \%$ and $94.9 \%$ ) while Ampara has 43.4\% Sri Lankan Moor, 38.9\% Sinhalese and 17.3\% Sri Lankan Tamils. There is also a small proportion of Tamils of Indian origin in Moneragala district (1.1\%) living in pockets in the large plantations. The estimated mid-year populations in 2013 were 658,000, 456,000 and 606,000 in Ampara, Moneragala and Hambantota districts, respectively, accounting for $8.4 \%$ of the country's population [8]. The main source of employment and economic activities relate to agriculture in all three districts.

\section{Methods}

\section{Study design, setting and population}

A descriptive cross-sectional household survey was conducted a on a randomly selected sample of residents in the 3 districts from February through May 2014. Data was collected from a key informant, usually the chief household or the spouse. Basic-socio demographic data was collected from all individuals who usually live in the households as residents irrespective of the ownership of the property. Any visitors or temporary residents who lived for a period of less than 1 year were excluded. Two adults over 20 years were also selected using an age-sex matrix to complete the section on non-communicable diseases. The vulnerable groups (pregnant, disabled, severely debilitated persons or young children less than 12 years) were excluded from interviews, though their basic details were obtained.

\section{Sampling method and sample size}

A three-stage stratified cluster sampling method was used to obtain a representative sample of the population. The 3 districts were considered as the strata. Selection of Divisional Secretary divisions, Grama Nildhari (GN) divisions (i.e. the smallest administrative unit with a welldefined boundary), and households was performed in the first, second and third stages of sampling, respectively.

The number of households required to estimate a proportion of $50 \%$ with $95 \%$ Confidence Intervals within $\pm 4 \%$ precision was 600 . The size of a cluster was determined as 15 households. In order to adjust for clustering effects considering the high diversity between and within the districts, an Intra Cluster Correlation Coefficient (ICC) of 0.15 was applied, and the corresponding design effect was 3.0 for the given cluster size. With a non-response rate of $8 \%$, the final sample size was 1950 households, which was drawn from 130 clusters with 15 households in each.

In the first stage of sampling, a sample of Divisional Secretary (DS) divisions were selected from each district, using a probability proportionate to size of the DS divisions. In the second stage, randomly $10 \mathrm{GN}$ divisions were identified as clusters from each DS division. "Census Blocks" used by the Department of Census and Statistics for national surveys were utilized to identify the houses within each cluster [9].

\section{Data collection}

The study team recruited an experienced team of enumerators who were previously employed in the Department of Census and Statistics to gather data. They 
were re-trained to obtain the relevant health related information, and to measure basic anthropometric data.

The selected clusters were listed according to DS divisions in each district. The cluster coordinator made a preliminary visit from the pre-identified starting point of the census block and followed instructions specified in the track to trace 15 households consecutively. During the preliminary visit, the cluster coordinator identified the key informant in each household for the household level data, and also selected 2 adults over 20 years using an age-sex matrix for the section on NCDs. These individuals were requested to remain at home during the data collection visit.

A pair of enumerators representing both gender visited each house. If the key persons were not available during this visit, the house was skipped and a substituted with a new household within the same area. The data collectors interviewed the informant using the questionnaire, and took basic anthropometric measurements.

\section{Survey instruments and equipment}

The research team perused several documents and developed an interviewer administered questionnaire with appropriate variables [9-12]. The questionnaire was available in all 3 languages and pre-tested among 20 households of 3 major ethnic groups - Sinhalese, Tamils and Muslims in the adjoining rural district of Badulla and revised. The variables were grouped under following 14 themes: (a) Household identification data; (b) Geographical positioning coordinates; (c) Socio-demographic data of household members; (d) Housing characteristics; (e) Non-communicable diseases; (f) Behavioural measurements; (g) Infectious and parasitic diseases; (h) Mental health; (i) Dog bites and elephant attacks; (j) Snake bites and poisoning; (k) Reproductive health; (l) Violence and crime; (m) Family relationships; and (n) Information on injury and death.

Portable digital weighing scales with high accuracy, wall mounted stadiometers and non-stretchable tape measures were used to measure height, weight and abdominal circumference respectively. All these equipment were of the recommended standards for research, and calibrated daily. The World Health Organization (WHO) standard procedures were followed to take anthropometric measurements. Global positioning system (GPS) coordinates were taken for other parts of the study, but are not presented in this paper.

\section{Data analysis}

The study team examined each completed questionnaire for completeness and validity of entries. Data was entered at 2 levels - household and individual level separately in customized data entry sheets and merged subsequently for the analysis.
Data analysis was performed using Statistical Package for Social Sciences (SPSS) version 20.0. The sampling probabilities in each of the 3 stages of sampling were calculated using 2012 census of population and housing data [9]. Sampling weights for the enumerating units (households) were estimated for each cluster, based on the respective sampling probabilities. All outputs were weighted accordingly. Basic analysis included summarization of outcome variables using proportions with 95\% confidence intervals to indicate prevalence estimates for the population. The outcome indicators are disaggregated by district.

\section{Ethics approval}

Ethics clearance was obtained from Ethics Review Committee of Faculty of Medicine, University of Colombo (Ref. No. EC-13-108). Informed written consent was obtained from the household head and/or the key informant before the interview.

\section{Results}

\section{Demographic profile}

Approximately 5\% of the listed households could not be either traced or interviewed. However, the anticipated sample size $(n=1950)$ was achieved by substituting houses within the same cluster (i.e. 900, 450 and 600 from Ampara, Moneragala and Hambantota districts, respectively). Of the total 1950 households visited, there were 8741 individuals indicating an average household size of 4.5 persons per house.

The Figure 1 illustrates the population pyramid, and the age distribution showed a middle-aged bulge seen in an ageing population. The dependency ratio was almost $50 \%$.

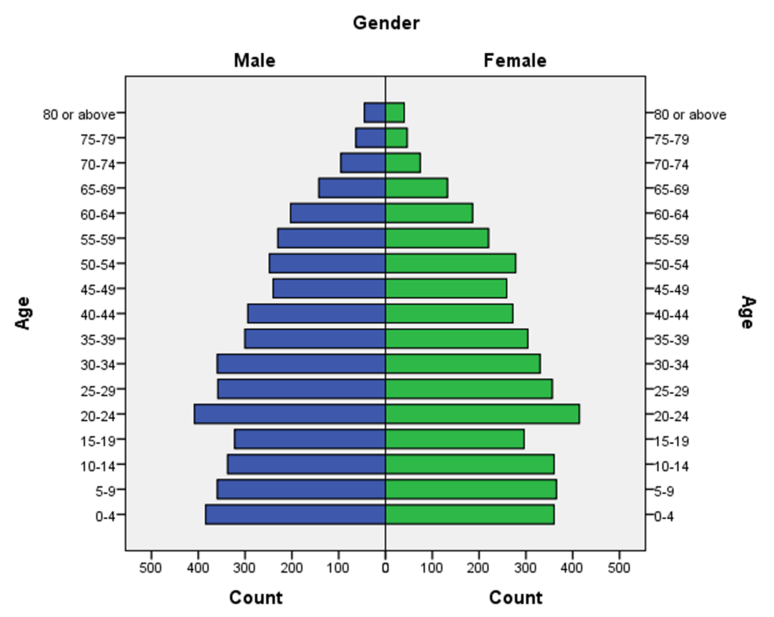

Figure 1. Distribution of all household members in the sample by age and sex (population pyramid). 


\section{Socio-economic characteristics}

As summarized in Table 1, almost $39 \%$ of the adults have completed at least General Certificate of Education (GCE) (ordinary level). The proportion not attended schools was $2.9 \%$, but the rate was higher in females $(3.8 \%$ compared to $2.1 \%$ of males) (data not shown in Table). Overall, about $16 \%$ had completed GCE (advanced level) or above. The Figure 2 shows the gradual decline in percentage of adults who passed GCE (advanced level) or above with the advancing age, indicating that younger generations are better educated than the elders.

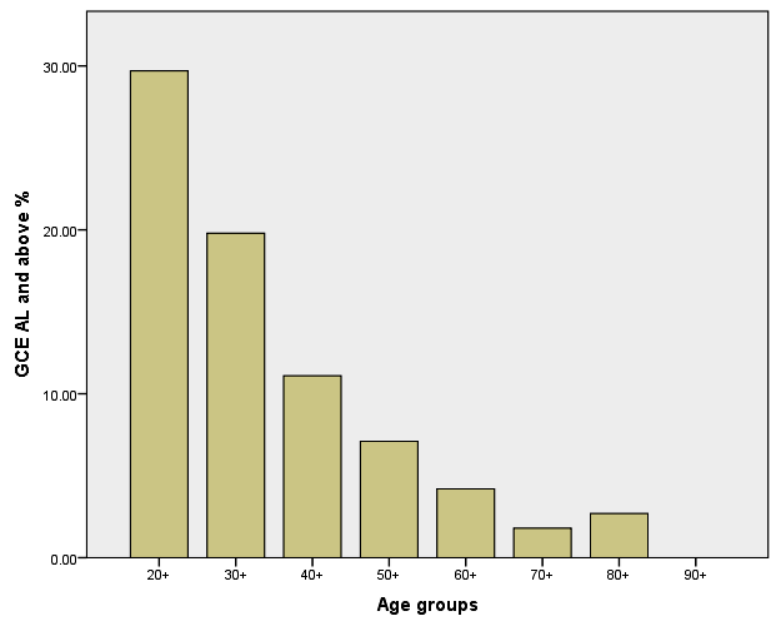

Figure 2. Educational achievement according to age, among adults aged 20 years and higher.
Unemployed was higher in females $(76.2 \%$ compared to $25.1 \%$ of males). Of the employed, most were engaged in agricultural and related work ( $22 \%$ of all adults), $10.9 \%$ in services sector and $7.2 \%$ of men were employed in armed forces.

\section{Household resources}

The access to safe drinking water and hygienic latrines was satisfactory (Table 2). Burning of refuse (72\%) was the commonest waste management practice. The households were mostly poor and there was a high proportion of houses that lacked basic amenities such as refrigerator $(60.9 \%)$. Most houses had electricity, ranging from $80.2 \%$ in Moneragala to $98.0 \%$ in Hambantota. Mobile phone use was popular $(89.1 \%)$ and a motorcycle or scooter was available in almost $50 \%$ of houses.

\section{Morbidity at household level}

Prevalence of key health issues as experienced by at least one person in the household are summarized in Table 3. Episodes on acute illness within preceding 2 weeks were noted from $35.9 \%$ of households, while a major injury in the past year was reported in $14.9 \%$ of households. The presence of a chronic illness was noted in $48.3 \%$ households. The report of malaria during the life time was very high $(37.9 \%)$ reflecting the endemicity of the illness in these areas in the past. Hepatitis was particularly high in Hambantota district (18.9\%). Relatively unusual causes of morbidities were noted: Snake bites experienced by $15.5 \%$ of households, dog bites by $9.7 \%$ by and attacks by elephants during the past 5 years by $1.1 \%$ households. Suicide or attempted suicide rate was $3.0 \%$, signifying its importance as a public health issue in these areas.

Table 1. Distribution of all males and females aged 18 years and above in the households according to education and employment

\begin{tabular}{|c|c|c|c|c|c|c|}
\hline & \multicolumn{6}{|l|}{ Sex } \\
\hline & \multicolumn{2}{|c|}{ Male } & \multicolumn{2}{|c|}{ Female } & \multicolumn{2}{|c|}{ All } \\
\hline & No & $\%$ & No & $\%$ & No & $\%$ \\
\hline \multicolumn{7}{|l|}{ Education level } \\
\hline Primary or lower & 705 & 21.7 & 687 & 21.7 & 1392 & 21.7 \\
\hline Grades 06 to 11 & 1268 & 41.4 & 1118 & 37.5 & 2386 & 39.5 \\
\hline GCE O/L & 676 & 22.4 & 672 & 22.9 & 1348 & 22.7 \\
\hline GCE A/L & 361 & 11.7 & 421 & 14.6 & 782 & 13.1 \\
\hline Diploma and Degree & 89 & 2.8 & 96 & 3.3 & 185 & 3.0 \\
\hline Total & 3099 & 100 & 2994 & 100 & 6093 & 100 \\
\hline \multicolumn{7}{|l|}{ Occupation } \\
\hline Unemployed & 759 & 25.1 & 2290 & 76.2 & 3049 & 50.3 \\
\hline Armed forces & 215 & 7.2 & 10 & 0.3 & 225 & 3.8 \\
\hline Managers / Professionals & 112 & 3.8 & 109 & 3.6 & 221 & 3.7 \\
\hline Technicians / Clerical support workers & 264 & 8.8 & 51 & 1.8 & 315 & 5.3 \\
\hline Service and sales workers & 457 & 15.9 & 152 & 5.8 & 609 & 10.9 \\
\hline Skilled agricultural, forestry and fishery workers & 1105 & 33.2 & 378 & 10.6 & 1483 & 22.0 \\
\hline Elementary and other occupations & 202 & 6.1 & 43 & 1.7 & 245 & 3.9 \\
\hline Total & 3114 & 100.0 & 3033 & 100.0 & 6147 & 100.0 \\
\hline
\end{tabular}

"Percentages have been weighted according to the sampling design 
Table 2. Access to water and sanitation, waste disposal methods, and availability of household assets by district ( $n=1950$ households)

\begin{tabular}{|c|c|c|c|c|c|}
\hline \multirow[t]{2}{*}{ Indicator $^{\mathrm{a}}$} & \multicolumn{2}{|c|}{$\%$ of households } & \multicolumn{3}{|c|}{ All districts } \\
\hline & Ampara & Moneragala & Hambantota & $\%$ & $95 \% C I$ \\
\hline Access to safe water & 91.0 & 91.7 & 84.8 & 89.0 & $87.6,90.4$ \\
\hline Access to hygienic latrines & 91.4 & 89.2 & 89.8 & 90.3 & $89.0,91.6$ \\
\hline \multicolumn{6}{|l|}{ Waste disposal practices ${ }^{\mathrm{b}}$} \\
\hline Dumping on the premises & 2.1 & 4.9 & 8.4 & 4.9 & $4.0,5.9$ \\
\hline Burning & 62.5 & 66.3 & 76.6 & 72.0 & $70.0,74.0$ \\
\hline Burying & 25.8 & 33.7 & 23.4 & 26.9 & $25.0,28.9$ \\
\hline Dumping on the road & 0.1 & 0.6 & 0.3 & 0.3 & $0.06,0.54$ \\
\hline Handing over to truck & 23.3 & 4.2 & 4.9 & 12.3 & $10.9,13.7$ \\
\hline Segregate and recycle & 4.8 & 1.8 & 3.4 & 3.6 & $2.8,4.4$ \\
\hline Composting of organic refuse & 18.6 & 18.1 & 13.7 & 16.8 & $15.2,18.4$ \\
\hline \multicolumn{6}{|l|}{ Household assets ${ }^{b}$} \\
\hline Electricity & 93.8 & 80.2 & 98.0 & 91.9 & $90.7,93.1$ \\
\hline Solar power & 1.3 & 8.9 & 0.3 & 2.8 & $2.1,3.5$ \\
\hline Television & 85.9 & 75.5 & 92.8 & 87.5 & $86.1,88.9$ \\
\hline Mobile phone & 90.8 & 82.5 & 91.8 & 89.1 & $87.7,90.5$ \\
\hline Refrigerator & 34.7 & 28.2 & 52.6 & 39.1 & $37.0,41.2$ \\
\hline \multicolumn{6}{|l|}{ Possession of vehicles ${ }^{b}$} \\
\hline Motorcycle/Scooter & 47.8 & 50.5 & 51.2 & 49.6 & $47.4,51.8$ \\
\hline Trishaw & 14.2 & 23.2 & 20.6 & 18.4 & $16.7,20.1$ \\
\hline Tractor/Land master & 16.1 & 13.5 & 10.0 & 13.3 & $11.8,14.8$ \\
\hline Motor car/van/bus/lorry & 3.1 & 5.1 & 9.8 & 6.0 & $5.0,7.0$ \\
\hline Total no. of households & 900 & 450 & 600 & 1950 & \\
\hline
\end{tabular}

${ }^{a}$ Percentages have been weighted according to the sampling design

${ }^{\mathrm{b}}$ Multiple responses allowed

CI - confidence intervals

Table 3. Morbidity at household level: Prevalence of key health issues experienced by at least one person in the household ( $n=1950$ households) ${ }^{a}$

\begin{tabular}{|c|c|c|c|c|c|}
\hline \multirow[t]{2}{*}{ Indicator a } & \multicolumn{2}{|c|}{$\%$ of households } & \multirow[b]{2}{*}{ Hambantota } & \multicolumn{2}{|c|}{ All districts } \\
\hline & Ampara & Moneragala & & $\%$ & $95 \% C I$ \\
\hline Acute illness during past 2 weeks & 34.2 & 28.1 & 43.8 & 35.9 & $33.8,38.0$ \\
\hline Chronic illness existing & 48.0 & 45.9 & 50.5 & 48.3 & $46.1,50.5$ \\
\hline Injury during the past year & 15.7 & 16.8 & 13.0 & 14.9 & $13.3,16.5$ \\
\hline Dog bite during the past year & 8.1 & 10.6 & 11.0 & 9.7 & $8.4,11.0$ \\
\hline Ever had a snake bite & 10.0 & 28.7 & 12.6 & 15.5 & $13.9,17.1$ \\
\hline Elephant attack during past 5 years & 2.3 & 0.6 & 0.0 & 1.1 & $0.64,1.6$ \\
\hline Ever had Leptospirosis & 1.8 & 3.9 & 2.8 & 2.7 & $2.0,3.4$ \\
\hline Ever had Malaria & 26.2 & 49.1 & 43.9 & 37.9 & $35.8,40.0$ \\
\hline Leishmaniasis in the past 5 years & 1.8 & 3.5 & 2.5 & 2.5 & $1.8,3.2$ \\
\hline Ever had Hepatitis & 3.2 & 6.6 & 18.9 & 9.4 & $8.1,10.7$ \\
\hline Ever committed/ attempted suicide & 2.7 & 3.6 & 2.9 & 3.0 & $2.3,3.8$ \\
\hline Total no. of households & 900 & 450 & 600 & 1950 & \\
\hline
\end{tabular}

a According to the key respondent whether anyone in the household had experienced these issues in the defined time period

${ }^{\mathrm{b}}$ Percentages are weighted according to the sampling design 


\section{Illness and behavior at individual level}

As shown in Table 4 , the adult population ( $\geq 20$ years) had considerably high prevalence of NCDs such as diabetes $(13.5 \%)$ and hypertension (16.7\%). The prevalence of risk factors such as overweight and obesity was in more than a quarter of adults (28.2\%) in these rural districts. Smoking (22.1\% in males), alcohol use (12.3\% in males) and betel chewing $(24.7 \%)$ were major adverse habits noted in large proportions of respondents.

Table 4. Morbidity at individual level: Prevalence of non-communicable disease and unhealthy behaviour among adults aged 20 years and above, selected for the interviewa

\begin{tabular}{|c|c|c|c|c|c|c|}
\hline $\begin{array}{l}\text { Prevalence } \\
(\% \text { of respondents })^{\mathrm{b}}\end{array}$ & Ampara & Moneragala & Hambantota & & All districts & \\
\hline & $\%$ & $\%$ & $\%$ & $\%$ & $95 \% C I$ & $n$ \\
\hline \multicolumn{7}{|l|}{ Non-communicable disease } \\
\hline Diabetes $^{\mathrm{c}}$ & 13.5 & 11.8 & 14.4 & 13.5 & $12.1,14.9$ & 2263 \\
\hline Hypertension $^{\mathrm{c}}$ & 16.3 & 19.1 & 15.7 & 16.7 & $15.4,18.1$ & 2857 \\
\hline Overweight and obesity & 30.5 & 23.2 & 28.8 & 28.2 & $26.8,29.6$ & 3884 \\
\hline \multicolumn{7}{|l|}{ Unhealthy behaviour } \\
\hline Betel chewing daily ${ }^{\mathrm{c}}$ & 26.4 & 27.6 & 20.7 & 24.7 & $23.4,26.1$ & 3770 \\
\hline Smoking among males ${ }^{\mathrm{e}}$ & 22.4 & 18.6 & 24.2 & 22.1 & $20.2,23.8$ & 1917 \\
\hline Alcohol use among males ${ }^{\mathrm{f}}$ & 10.7 & 14.2 & 12.7 & 12.3 & $10.8,13.7$ & 1917 \\
\hline
\end{tabular}

${ }^{\text {a }}$ One male and one female aged 20 years or above per household were included for this assessment

${ }^{\mathrm{b}}$ Percentages have been weighted according to the sampling design

${ }^{c}$ According to self-reporting by selected adults at the time of survey

${ }^{\mathrm{d}}$ According to direct measurements at the time of survey, Body Mass Index $\geq 25.0 \mathrm{kgm}^{-2}$

${ }^{\mathrm{e}}$ Males who smoked daily at the time of survey

${ }^{\mathrm{f}}$ Males who consumed alcohol daily or few days per week at the time of survey

\section{Discussion}

Sri Lanka is considered to have a predominantly rural population (estimated as $81.9 \%$ of the population) [9], and this study provides the first comprehensive description of rural health in Sri Lanka. The results demonstrate a triple burden of issues: a changing demography to an older cohort, high prevalence of NCDs and injuries, and health problems that are likely to be specific to rural areas (e.g. impacts of previous malarial morbidity, snake bite and deliberate self-harm). Furthermore, the people are economically deprived and have a high rate of unemployment, which would contribute to some of the diseases and impede access to quality health care.

The age structure shows a high dependency ratio (of $47.7 \%$ ) characteristic of the rest of the country, due to falling fertility rates and extended life span. This is further demonstrated by the middle-age bulge as seen in the age pyramid. The high prevalence of diabetes $13.5 \%$, hypertension $16.7 \%$, compares to the average national figures (of $10.3 \%$ and $15.7 \%$ respectively) [4, 5]. A surprising finding was the high rates of overweight/obesity (28.2\%) in the rural environment. Taken together with data from previous studies, it indicates that Sri Lankan rural populations are developing these chronic diseases at an alarming rate $[5,11]$. The aetiology is likely to be related to changing diet (i.e. high calorie diets) and decreasing levels of physical activity. Another potential aetiological factor is the use of agrochemicals. Several studies have reported that persistence of compounds such as dichlorodiphenyltrichloroethane (DDT) in the environment leads to diabetes and other metabolic effects through disruption of endocrine receptors [12]. The data also challenges the common belief that these disorders and diseases are mainly urban phenomena. The high prevalence of NCDs also highlights the urgency to identify likely determinants, aetiological factors and tackle these in the rural communities.

Of the households studied, there were episodes of acute illness in the preceding 2 weeks in $35.9 \%$, and injuries in the past year in $14.9 \%$. This may reflect a deprived environment and types of exposure seen in high-risk occupation (e.g. agricultural practices). There was also a high burden from snakebites, reported previously by other authors (32,902 snakebites annually in 18.96 million population) [13]. The contribution of snakebites to the burden of chronic kidney disease is now being recognized and the resultant burden is likely to be significant [14]. A study conducted in parallel to this in Ampara district 
showed that $3.2 \%$ of the victims of snake envenoming, had musculoskeletal disabilities persisting for months to years since the snakebite [15].

Suicides or attempted suicides were reported in $3 \%$ of households, indicating a high rate of suicide in rural agricultural communities. The predominance of deliberate self-harm in rural populations is well known [16]. The suicide rate in Sri Lanka was 18.5 per 100,000 population in 2011 [16], which points towards the role of sociological and/or psychological services in the community that needs to be addressed rather urgently.

The high rate of past history of malaria was expected from these areas because they have faced the brunt of epidemics in the past. The burden from malaria would have had a major impact on the rural productivity and cognitive development of children $[17,18]$.

The population living in the three study districts could be considered as the most economically deprived and engaged predominantly in agricultural occupations [10]. However, the female unemployment was almost 3 times higher than the males reflecting the deprived status of rural women in relation to employment opportunities.

The results show that, despite having an extensive network of state funded non-fee levying schools, the education level of the population is relatively poor, with only $38.8 \%$ educated to GCE (ordinary level) and above. The proportion who had passed examination had progressively increased every decade demonstrating an improvement in educational achievements by successive cohorts. There was no appreciable inequality in educational achievement by gender which suggests a lack of gender discrimination in access to education.

Overall, the results showed that the rural Sri Lankan population is affected by multiple health issues that are further aggravated by socio-economic context and the environment. The study also gives direction to policymakers of priority areas to allocate resources for provision of services and prevention such as obesity and noncommunicable disease such as diabetes, hypertension and chronic kidney disease, and future disabilities such as stroke and blindness from diabetes. There is also a need to focus on psychosocial issues in these communities with high rates of deliberate self-harm. The results indicate the need is to provide universal access to continuing care that makes the optimum use of the existing health system and the resources. The present study supports a transition from the episodic type of patient management to a continuing personalized and family centered care which is much more appropriate in addressing the non-communicable disease and risk factors. The initiative of the Ministry of Health for restructuring primary health care with shared care cluster system would be a timely intervention [23-24].

The study had few limitations. Most of the morbidities were based on self-reported data which is less reliable. Certain illnesses would have been underreported, due to the subjects being unaware of their illness. The key strengths of the survey include the population representativeness in sampling, larger sample size, household-based data collection process, and weighting of results to the population in the analysis. For NCDs, age-sex representativeness was assured using a grid when identifying the participants in the appropriate target groups.

\section{Conclusions}

This study gives an overall view of rural health in Sri Lanka. It provides a rich source of baseline health information on a wide range of health issues of a rural population, that would be useful for policy makers and programme planners. The findings reflect high burden of disease in rural Sri Lanka and warrants detailed analyses to identify determinants of these illnesses and health seeking patterns, in order to improve both preventive and curative services.

\section{Acknowledgments}

The authors wish to express sincere gratitude to the World Bank for providing funds for the study under the grant HETC/QIG/W3. The authors also wish to acknowledge the support extended by the Ampara, Kalmunai, Moneragala and Hambantota Regional Directors of Health Services, and their staff.

\section{Availability of data}

Data will not be available at individual level due to ethical reasons.

\section{Conflict of interests}

There are no conflicts of interests.

\section{References}

1. World Health Organization. WHO Country Cooperation Strategy Sri Lanka 2012-2017, Colombo: WHO Country Office for Sri Lanka, 2012.

2. Ministry of Health, Nutrition and Indigenous Medicine. Annual Health Statistics 2012, Colombo: Ministry of Health, 2012.

3. Epidemiology Unit, Ministry of Health Nutrition and Indigenous Medicine Quarterly Epidemiological Bulletin 2012 Second Quarter. Colombo: Ministry of Health, 2012. http:// www.epid.gov.lk (accessed on 01 Feb 2017).

4. Katulanda P, Constantine GR, Mahesh JG, et al. Prevalence of diabetes and pre-diabetes in adults in Sri Lanka. Sri Lanka Diabetes, Cardiovascular Study (SLDCS). Diabetic Medicine, 2008: 25 (9): 1062-9.

5. Katulanda P, Sheriff MH, Mathews DR. Diabetes epidemic in Sri Lanka - a growing problem. Ceylon Med $J$. 2006, 51(1): 26-8. 
6. National Cancer Control Programme, Ministry of Health Nutrition and Indigenous Medicine. Cancer Incidence Data: Sri Lanka year 2001-2005, Colombo: National Cancer Control Programme, 2009.

7. Institute for Research and Development (IRD) and Ministry of Health Nutrition and Indigenous Medicine. National Mental Health Survey, Colombo: Ministry of Health, 2012.

8. Department of Census and Statistics, Sri Lanka. Statistical Abstracts 2014. Colombo: Department of Census and Statistics, 2014.

9. Department of Census and Statistics, Sri Lanka.. Population \& Housing Data 2012. Colombo: Department of Census and Statistics, 2012.

10. Department of Census and Statistics, Sri Lanka. Household Income and Expenditures Survey 2009-2010, Colombo: Department of Census and Statistics, 2012.

11. Wijewardene K, Mohideen MR, Mendis S, et al. Prevalence of hypertension, diabetes and obesity: baseline findings of a population based survey in four provinces in Sri Lanka. Ceylon Med J. 2005; 50: 62-70.

12. Gilffors R, Siribaddana S, Forbes S, Eddleston M. Endocrine-disrupting chemicals and the diabetes epidemic in countries in the WHO South-East Asia region. Lancet Diabetes Endo. 2015; 3 (12): 925-27.

13. Kasturiratne A, Wickremasinghe AR, de Silva N, Gunawardena NK, Pathmeswaran A, Premaratna R, et al. The Global Burden of Snakebite: A Literature Analysis and Modelling Based on Regional Estimates of Envenoming and Deaths. PLoS Med. 2008; 5(11): e218.

14. Herath HM, Wazil AW, Abeysekara DT, et al. Chronic kidney disease in snake envenomed patients with acute kidney injury in Sri Lanka: a descriptive study. Postgrad Med J. 2012; 88: 138-42.

15. Jayawardana S, Gnanathasan A, Arambepola C, Chang T. Chronic Musculoskeletal Disabilities following Snake
Envenoming in Sri Lanka: A Population-Based Study. PLOS Neglect Trop D. 2016, 10(11): e0005103.

16. Knipe DW, Padmanathan P, Muthuwatta L, Metcalfe C, Gunnell D. Regional variation in suicide rates in Sri Lanka between 1955 and 2011: a spatial and temporal analysis. BMC Public Health. 2017; 17(1):193.

17. Fernando D, de Silva D, Wickremasinghe R. Short-term impact of an acute attack of malaria on the cognitive performance of schoolchildren living in a malaria-endemic area of Sri Lanka. Trans $R$ Soc Trop Med Hyg. 2003, 97: 633-9.

18. Fernando SD, Gunawardena DM, Bandara MRSS, et al. The impact of repeated malaria attacks on the school performance of children. Am J Trop Med Hyg. 2003, 69: 582-8.

19. Department of Census and Statistics, Sri Lanka. Sri Lanka Demographic and Health Survey 2006-7. Colombo: Department of Census and Statistics, 2009.

20. Central Bank of Sri Lanka. Annual Report 2011. Colombo: Central Bank, 2012.

21. Family Health Bureau, Ministry of Health Nutrition and Indigenous Medicine. Annual Report on Family Health 2010. Colombo: Ministry of Health, 2012.

22. International Labour Organization. International Standard Classification of Occupations 2008 (ICSO-08). Geneva: ILO, 2008.

23. Perera S. Primary health care reforms in Sri Lanka: aiming at preserving universal access to health. In: Medcalf AJ, Bhattacharya S, Momen H, Saavedra MA, Jones M. eds. Health for all: the journey of universal health coverage. Hyderabad: Orient Blackswan, 2015: 82-6.

24. Ministry of Health, Nutrition and Indigenous Medicine. National Health Strategic Master Plan 2016-2025. Colombo: Ministry of Health, 2016. 